\title{
Change in Knowledge and Reported Use of Sport Science by Elite New Zealand Olympic Class Sailors
}

\author{
Stephen J. Legg and Hamish W. Mackie\# \\ Department of Management Systems, Massey University
}

\begin{abstract}
The objective of this study was to examine the change in knowledge and use of sport science in 46 elite New Zealand Olympic class dinghy sailors' one year after the adoption of a sport science support (SSS) programme by Yachting New Zealand. Twenty eight (22 males, six females) sailors responded to a questionnaire which was administered during a training camp in April 1994 and 28 (also 22 males and six females) responded to the same questionnaire at a training camp in April 1995. Ten of the sailors responded in both 1994 and 1995. The questionnaire asked whether or not the sailors used a training race diary and inquired about their knowledge and use of sport science in the areas of nutrition, psychology and physical conditioning. In 1995, additional questions enquired about sailors' perception of sport science and its affect on their racing performance. In the intervening year, six of the sailors received sport science support (SSS) in nutrition; eleven received SSS in sport psychology; eleven received SSS in physical conditioning. In 1995, the sailors reported a greater amount of fluid taken and drunk on a fourhour sail and a greater proportion of sailors ate a high carbohydrate meal after a race. They also reported feeling less anxiety before a race. Increases were also observed in the sailors' volume and intensity of physical training and in their chosen type of aerobic training. Most sailors believed that their knowledge and use of sport science had increased and that this had led to improvements in racing performance. It is concluded that elite New Zealand sailors' reported use of sport science improved in the areas of physical conditioning and nutrition between 1994 and 1995. Improvement in the use of sports psychology was less clear and the eleven sailors who received psychology SSS reported feeling more anxious before a race. There was little evidence to suggest that the sport science programme was responsible for the improvements. This study indicates that sailors are beginning to understand the importance of sport science support, but there is still
\end{abstract}

"Present: Department of Sport Sciences, Faculty of Health Sciences and Technology, UNITEC much room for improvement in their use of sport science. (J Physiol Anthropol 19 (2): 83-92, 2000)

Keywords: nutrition, psychology, physical conditioning, sport science, sailing, questionnaires

\section{Introduction}

Most studies related to dinghy racing have concentrated on the physiological demands of sailing (Bachemont et al., 1984; Blackburn, 1994; DeVito et al., 1996; DeVito et al., 1997; Gallozzi et al., 1993; Harrison et al., 1988; Pudenz et al., 1981; Vogiatzis et al., 1993; Vogiatzis et al., 1994), while others have studied the biomechanics of dinghy racing (Beillot et al., 1979; Beillot et al., 1981; Mackie and Legg, 1999; Mackie et al., 1999; Marchetti et al., 1980; Putnam, 1979), physical profile of sailors (Legg et al., 1997; Niinimaa et al., 1977; Plyley et al., 1985; Shephard, 1990), sailors' responses to physical training programmes (Spurway and Burns, 1993; Wright et al., 1976) and the psychological aspects of dinghy racing. However, little is known about the application of sport science to dinghy racing and about sailor's knowledge and use of sport science.

In 1994, Legg et al. (1997) administered a questionnaire to 28 elite New Zealand Olympic class dinghy sailors inquiring about their knowledge and use of sport science. The extent of sailors' sport science knowledge in the areas of nutrition, sport psychology and physical training generally appeared to be modest to good, but was poor for a small number of sailors and in some specific areas. It was concluded that there was considerable scope for improvement of knowledge and use of sport science amongst elite New Zealand Olympic Class sailors.

As a result of this study Yachting New Zealand (the administrative body for yachting in New Zealand) adopted a sport science support (SSS) programme for elite dingy sailors, utilizing the expertise of specialists in nutrition, sports psychology and physical conditioning.

The objective of the present study was to examine the changes in knowledge and use of sport science in elite New Zealand Olympic class dinghy sailors one year after the 
adoption of a sport science support programme by Yachting New Zealand.

\section{Methods}

In April 1994, 28 (22 males, 6 females, mean age 22.6 (SD 5.6) years, height 169.3 (SD 33.8) cm and weight 69.4 (SD 9.2) kg) elite New Zealand Olympic Class sailors completed a short questionnaire which enquired about their knowledge and use of sport science in the areas of nutrition, sport psychology and physical training (Legg et al., 1997). The group consisted of 8 (5 males, 3 females) Mistral, 2 (males) Finn, 1 (female) Tornado, 6 (5 males, 1 female) Laser, 1 (female) Europe and 10 (6 helmsmen (5 males, 1 female) and 4 (male) crew) 470 sailors. The questionnaire was administered to all of the sailors at the same time as part of an introductory seminar on sport science support. It took approximately 5 minutes to complete.

The nutrition questions enquired whether or not the sailors had experienced dehydration during racing, requested a subjective quantification of how much fluid they took on the boat for a 4-hour sail and how much they actually drank, and asked what they ate immediately after a long hard race.

The psychology questions required the sailors to select a response by ticking one of 5 boxes labelled "Never, Sometimes, Often, Very often and All of the time" to the following questions: 1. Before racing, do you get a) anxious? b) sweaty palms? c) a sick feeling in your stomach? 2. During a race do you a) get frustrated when you make mistakes? b) get angry at other sailors? c) have negative thoughts? d) lose concentration near the end of the race? The sailors were also asked whether or not they practised relaxation, visualisation, progressive muscular relaxation, meditation or yoga.

The physical training questions enquired about their use of a training/race diary and their type of training/ conditioning (strength/circuit, flexibility, aerobic (off water and on water), and the number of sessions, their intensity (low, moderate or high) and total hours per week devoted to each type of training. The sailors were also asked to specify the type of aerobic training they did.

During the year that followed, 12 of the sailors in the group received sport science support from specialists in nutrition, psychology and physical conditioning. Sailors visited the relevant sport science specialist depending on their personal needs. Six of the sailors visited a nutritionist, 11 of the sailors visited a sport psychologist and 11 of the sailors visited a physical conditioner. Five sailors visited the sport science specialist once only, and 7 sailors visited a physical conditioner between twice and five times. At each visit, nutrition, psychological and physical conditioning advice were prescribed, depending on the specific needs of the individual sailor. Adherence to this advice was then reliant on the sailor.

In April 1995, at an Olympic training camp, the same questionnaire was administered to 28 sailors, comprising 10 of the 1994 group and 18 newcomers (22 males, 6 females, mean age 25.9 (S.D. 7.3) years, height 176.8 (S.D. 8.1) $\mathrm{cm}$ and weight 73.6 (S.D. 9.6) kg). The 1995 group consisted of 4 Europe (females), 7 Laser (males), 3 Finn (males), 5470 (helm (2 females, 3 males)), 5470 (crew (males)), 2 Tornado (helm (males)) and 2 Tornado (crew (males) sailors. Additional questions were included asking sailors if their overall knowledge and use of sport science had increased, and whether they thought sport science had helped to improve their overall racing performance. Sailors were also asked to exemplify their answers.

Analyses of the responses focused on three different areas. Firstly, all of the 1994 data were compared with the 1995 results. Secondly, the results for the ten subjects common to 1994 and 1995 were compared so that a longitudinal comparison could be made. Lastly, within the 1995 data, the results of those sailors who received sport science support (SSS) over the previous year were compared with the results of those sailors who received no sport science support (NSSS).

Student's $t$-tests were used to compare the differences in continuous numerical answers. For the comparison of all 1994 subjects with all 1995 subjects and the comparison of the SSS and NSSS subjects in 1995, unpaired $t$-tests were used. Paired $t$-tests were used for the longitudinal comparisons of those subjects common to the 1994 and the 1995 group. Meddis's rank scores test was used to compare discrete answers such as those using a 1-5 scale or "yes"/ "no" type answer.

\section{Results}

\section{Nutrition}

Comparison between 1994 and 1995 data: The mean reported amount of water taken on a four hour sail increased from 0.9 (S.D. 0.6) litre (1) in 1994 to 1.6 (S.D. $0.9) \mathrm{l}$ in $1995(\mathrm{P}<0.01)$ (Table 1$)$. Of this, the amount actually drunk increased from 0.9 (S.D. 0.5) l in 1994 to 1.2 (S.D. 0.7) l in $1995(\mathrm{P}<0.05)$. The proportion of subjects that reported experiencing dehydration increased from $68 \%$ in 1994 to $75 \%$ in 1995 , and the proportion of sailors that reported eating high carbohydrate food after a race increased from 54\% in 1994 to 68\% in 1995 . However, neither of these findings were statistically significant.

Comparison between results from subjects common to 1994 and 1995: There was an increase in the proportion of sailors reporting eating high carbohydrate food after a race from $30 \%$ in 1994 to $70 \%$ in 1995 $(p<0.05)$. There were also non statistically significant increases in mean reported amounts of fluid taken and drunken on a 4-hour sail of 0.8 (S.D. 0.5) 1 in 1994 to 1.1 
Table 1 The effect of sailor's use of nutrition sport science support (SSS)

\begin{tabular}{|c|c|c|c|c|c|c|}
\hline & \multicolumn{2}{|c|}{$\begin{array}{l}\text { Comparison of all } \\
\text { subjects data }\end{array}$} & \multicolumn{2}{|c|}{$\begin{array}{l}\text { Comparison of } \\
\text { subjects data common } \\
\text { to } 1994 \text { and } 1995\end{array}$} & \multicolumn{2}{|c|}{$\begin{array}{l}\text { Effect of nutrition } \\
\text { SSS }\end{array}$} \\
\hline & 1994 & 1995 & 1994 & 1995 & SSS & No SSS \\
\hline Number of subjects & $\mathrm{n}=28$ & $\mathrm{n}=28$ & $\mathrm{n}=10$ & $\mathrm{n}=10$ & $\mathrm{n}=6$ & $\mathrm{n}=15$ \\
\hline $\begin{array}{l}\text { Have you ever experienced dehydration } \\
\text { during racing? (\% "yes") }\end{array}$ & 68 & 75 & 70 & 70 & 67 & 73 \\
\hline $\begin{array}{l}\text { Volume of fluid (I) taken on a four } \\
\text { hour sail }\end{array}$ & $0.9(0.6)$ & $1.6(0.9) * *$ & $0.8(0.5)$ & $1.1(0.3)$ & $1.7(0.5)$ & $1.4(1.0)$ \\
\hline $\begin{array}{l}\text { Volume of fluid (I) drunk on a four } \\
\text { hour sail }\end{array}$ & $0.9(0.5)$ & $1.2(0.7)^{*}$ & $0.7(0.6)$ & $1.0(0.3)$ & $1.6(0.6)$ & $1.1(0.7)$ \\
\hline $\begin{array}{l}\text { Percentage of subjects reporting eating } \\
\text { high carbodydrate food after a long hard race }\end{array}$ & 54 & 68 & 30 & $70 *$ & 67 & 60 \\
\hline
\end{tabular}

(S.D. 0.3) $l$ in 1995 and 0.7 (S.D. 0.6) l in 1994 to 1.0 (S.D. $0.3) \mathrm{l}$ in 1995 respectively.

Effect of nutrition sport science support (SSS): No statistically significant differences were observed in subject's reported nutrition habits between those who received nutrition SSS and those who did not receive SSS. However, of those who received nutrition SSS, a lesser proportion of subjects reported experiencing dehydration (67\% compared with 73\% (no SSS)). Greater mean amounts of fluid taken and drunk on a 4-hour sail was reported (1.7 (S.D. 0.5) l taken and 1.6 (S.D. 0.6) l drunk compared with 1.4 (S.D. 1.0) l taken and 1.1 (S.D. 0.7) l drunk (no SSS)) and a greater proportion of subjects reported eating high carbohydrate food (67\% compared with 60\% (no SSS)).

\section{Psychology}

Comparison between 1994 and 1995 data. All subjects: A greater proportion of sailors reported feeling less anxious before a race in 1995 (18\% feeling 'not at all anxious') than in 1994 (none feeling 'not at all anxious') $(p<0.05)$ (Fig. 1). Although the differences were not statistically significant, 36\% of sailors in 1995 reported never getting a sick feeling in their stomach before racing compared with $25 \%$ in 1994, only $4 \%$ of sailors in 1995 reported feeling frustrated very often when they made mistakes compared with $18 \%$ in 1994 and $82 \%$ of sailors in 1995 reported using visualization compared with 64\% in 1994. There were no clear differences in the proportions of sailors who reported having sweaty palms before racing, getting angry at other sailors, having negative thoughts and losing concentration near the end of a race.

Comparison between results from subjects common to 1994 and 1995: More sailors reported feeling less anxious in 1995 (20\% feeling 'not at all anxious') than did those in 1994 (none feeling 'not at all anxious') $(\mathrm{p}<0.05)$ (Fig. 2). Although not statistically significant, a greater proportion of sailors in 1995 (60\%) reported sometimes getting frustrated when they made mistakes than did those in 1994 (30\%), but more sailors in 1994 (50\%) reported often getting frustrated when they made mistakes than did those in 1995 (30\%). There were no clear differences in the proportions of sailors reporting sweaty palms before racing, getting a sick feeling before racing, getting angry at other sailors, having negative thoughts and losing concentration at the end of a race. Only $50 \%$ of sailors reported practicing relaxation in 1995 compared with 80\% in 1994, but this difference was also not statistically significant.

Effect of psychology sport science support (SSS): Out of those who received no psychology sport science support, 33\% of sailors reported never feeling anxious before a race while none of the sailors that received psychology sport science support reported never feeling anxious before a race in $1995(\mathrm{p}<0.01)$ (Fig. 3). Also, 18\% of those who received psychology sport science support reported feeling very anxious before a race while no sailors that received no psychology sport science support reported feeling very anxious before a race. Similarly, a greater proportion of sailors (20\%) who received no psychology SSS reported never getting angry at other sailors compared with no sailors who received psychology SSS never getting angry at other sailors. There were no statistically significant differences in the proportion of sailors feeling sick before a race, getting sweaty palms before racing, getting frustrated when they make mistakes, having negative thoughts during a race, losing concentration near the end of a race and practicing relaxation, visualisation, progressive muscular relaxation, meditation or yoga between those who received psychology SSS and those 


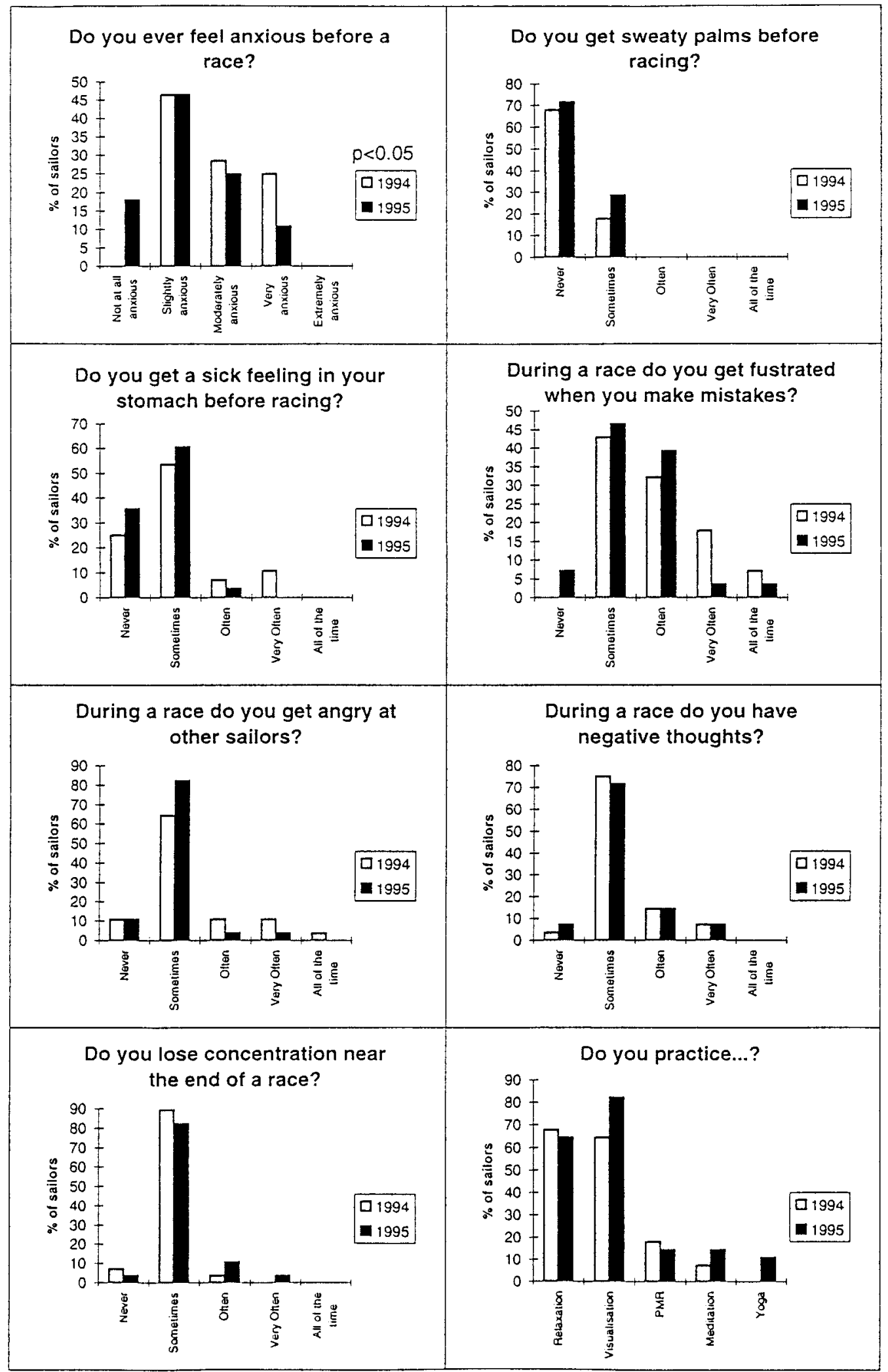

$\mathrm{p}<0.05$ represents a statistically significant difference at the $5 \%$ level of probablility.

Fig. 1 Comparison of sailor's use of psychology in 1994 and 1995. 


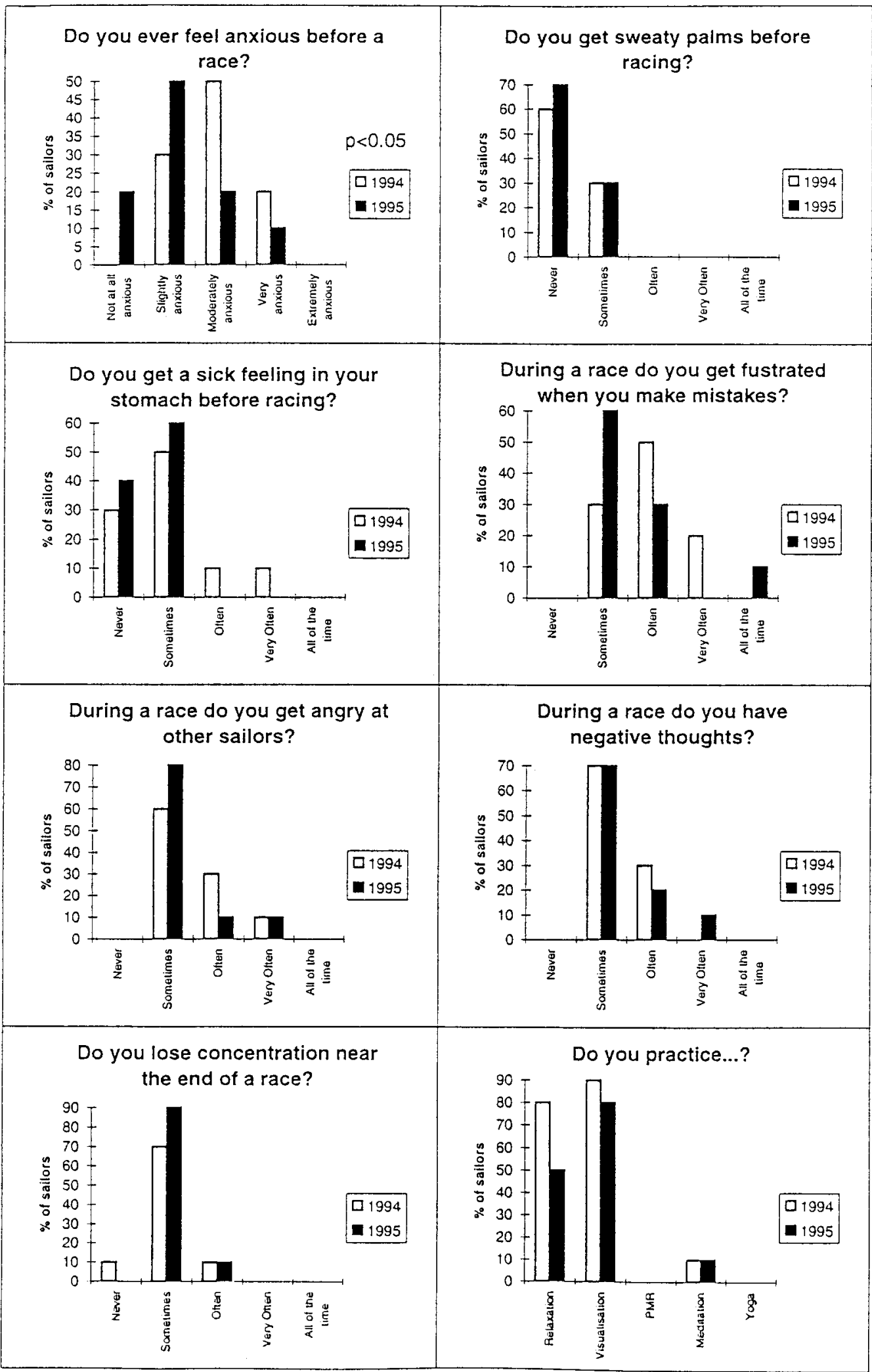

$\mathrm{p}<0.05$ represents a statistically significant difference at the $5 \%$ level of probablility.

Fig. 2 Comparison of use of psychology for sailors common to 1994 and 1995. 


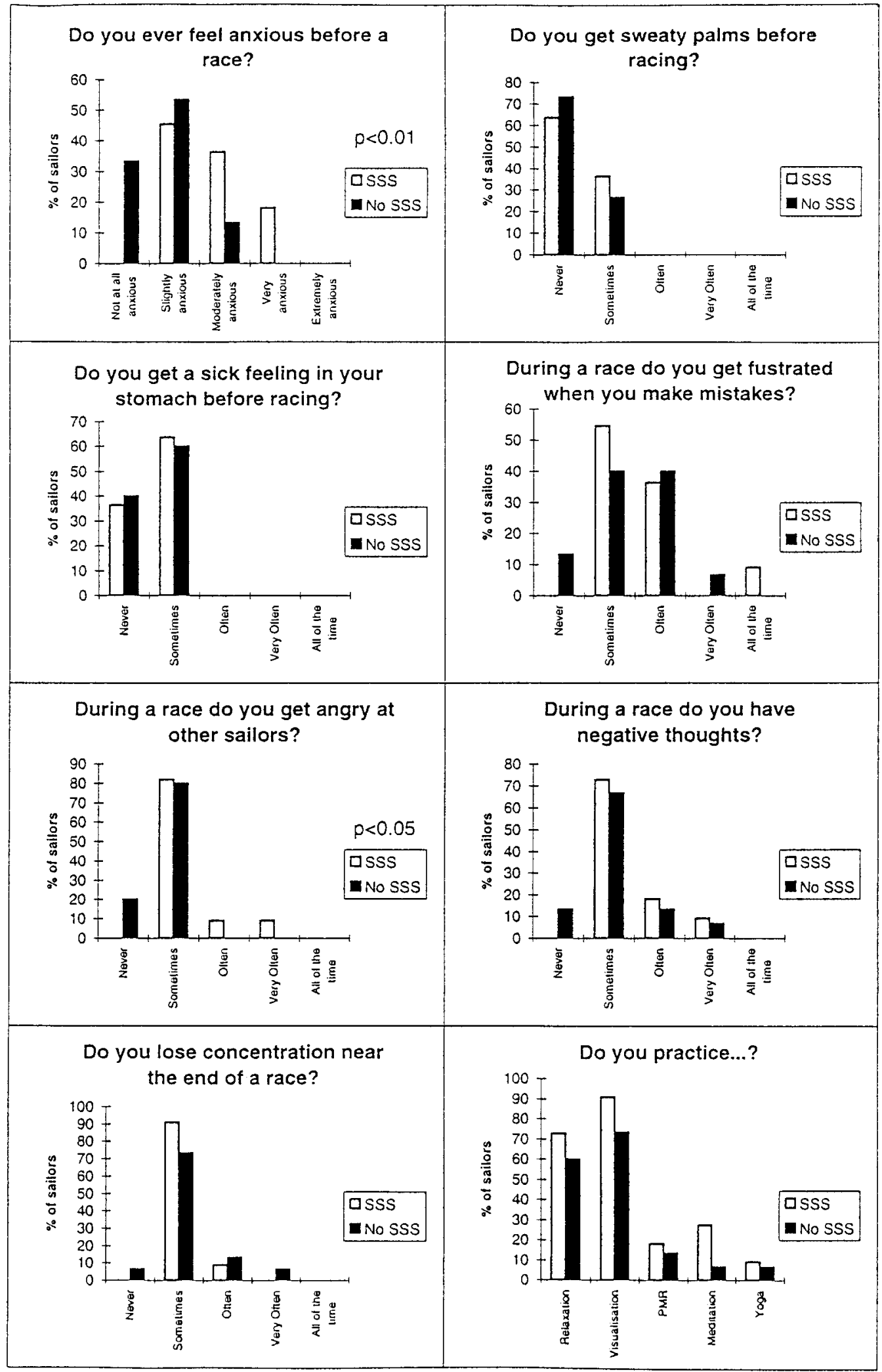

$\mathrm{p}<0.05$ represents a statistically significant difference at the $5 \%$ level of probablility. $\mathrm{p}<0.01$ represents a statistically significant difference at the $1 \%$ level of probablility.

Fig. 3 Comparison of use of psychology for sailors who received psychology sport science support (SSS) and those who received no psychology SSS. 
who received no psychology SSS.

\section{Physical conditioning}

Comparison between 1994 and 1995 data:

\section{Training and race diary}

In $1995,57 \%$ of sailors used a training and race diary compared with 39\% of sailors in 1994. The difference was non-significant.

\section{Strength/circuit training}

More subjects reported participating in strength training in 1995 (86\%) compared with 1994 (54\%) $(p<0.01)$ (Table 2). Likewise, a greater mean number of strength/circuit training sessions per week were reported in 1995 (2.6 (S.D. 1.4) compared with 1.3 (S.D. 0.5) in 1994 $(p<0.01))$. Similarly, a greater mean training intensity was reported in 1995 (2.5 (S.D. 0.5) compared with 1.7 (S.D. $0.5)$ in $1994(\mathrm{p}<0.001))$, and a greater mean total hours per week participating in strength/circuit training was reported (3.5 (S.D. 2.5) hours) compared with 1.9 (S.D. 2.4) hours in $1994(\mathrm{p}<0.05))$.

\section{Flexibility training}

In 1995, more subjects reported participating in flexibility training (71\% compared with 39\% in 1994 $(p<0.01))$. There were also increases in the mean number of sessions per week (3.1 (S.D. 2.3) compared with 1.4 (S.D. $2.5)$ in $1994(\mathrm{p}<0.01))$ and the mean total number of hours per week (1.4 (S.D. 1.5) compared with 0.4 (S.D. 0.7) in $1994(\mathrm{p}<0.01))$ spent participating in flexibility training.

\section{Aerobic off-water conditioning}

A greater mean exercise intensity was reported in 1995 (2.2 (S.D. 0.5) on a scale of 1-3) than was reported in 1994 (1.7 (S.D. 0.6) $(\mathrm{p}<0.01))$. Non-significant increases in reported participation (82\% of subjects in 1995 compared with $64 \%$ in 1994), mean reported sessions per week (2.5 (S.D. 1.4) in 1995 compared with 1.9 (S.D. 1.9) in 1994) and mean total hours per week (2.6 (S.D. 1.8) hours in 1995 compared with 1.9 (S.D. 1.9) hours in 1994) were also observed. However, a greater proportion of sailors participated in cycling (54\%) and rowing (43\%) in 1995 than in 1994 (cycling, 14\% and rowing 7\%) ( $<<0.01)$.

\section{On-water conditioning}

Increases in the mean reported number of sessions per week (4.0 (S.D. 1.4) in 1995 compared with 2.7 (S.D. 1.8) in $1994(\mathrm{p}<0.01))$, and the mean reported intensity $(2.3$ (S.D. 0.6) in 1995 compared with 1.8 (S.D. 0.5) in 1994 $(p<0.01))$ were observed. There was a non-significant increase in the mean reported total number of hours spent participating in on-water conditioning (10.3 (S.D. 5.1) in 1995 compared with 8.5 (S.D. 6.2) in 1994).

Comparison between results from subjects common to 1994 and 1995:

Table 2 The effect of sailors use of physical conditioning sport science support (SSS)

\begin{tabular}{|c|c|c|c|c|c|c|}
\hline & \multicolumn{2}{|c|}{$\begin{array}{l}\text { Comparison of all } \\
\text { subjects data }\end{array}$} & \multicolumn{2}{|c|}{$\begin{array}{l}\text { Comparison of } \\
\text { subjects data common } \\
\text { to } 1994 \text { and } 1995\end{array}$} & \multicolumn{2}{|c|}{$\begin{array}{l}\text { Effect of physical } \\
\text { conditioning SSS }\end{array}$} \\
\hline & 1994 & 1995 & 1994 & 1995 & SSS & NSSS \\
\hline Number of subjects & $\mathrm{n}=28$ & $\mathrm{n}=28$ & $\mathrm{n}=10$ & $\mathrm{n}=10$ & $\mathrm{n}=11$ & $\mathrm{n}=15$ \\
\hline $\begin{array}{l}\text { Percentage of sailors keeping a detailed training } \\
\text { and race diary }\end{array}$ & 39 & 57 & 50 & 70 & 58 & 53 \\
\hline Strength/Circuit training (\% participation) & 54 & $86^{* *}$ & 50 & 80 & 82 & 93 \\
\hline Sessions per week & $1.3(1.5)$ & $2.6(1.4)^{* *}$ & $1.3(1.5)$ & $2.2(1.5)^{*}$ & $2.3(1.6)$ & $2.8(1.3)$ \\
\hline Intensity $(1=$ low, $3=$ high $)$ & $1.7(0.5)$ & $2.5(0.5) * * *$ & $2.0(0.0)$ & $2.4(0.5)$ & $2.8(0.4)$ & $2.0(0.5)^{* *}$ \\
\hline Total hours per week & $1.9(2.4)$ & $3.5(2.5)^{*}$ & $1.5(2.3)$ & $2.65(1.9)$ & $3.7(3.3)$ & $3.3(2.0)$ \\
\hline Flexibility (\% participation) & 39 & $71 * *$ & 40 & $80^{* *}$ & 82 & 67 \\
\hline Sessions per week & $1.4(2.5)$ & $3.1(2.3) * *$ & $1.9(3.4)$ & $3.6(2.2)$ & $3.5(2.0)$ & $3.0(2.5)$ \\
\hline Intensity ( $1=$ low, $3=$ high $)$ & $2.0(1.1)$ & $2.0(0.6)$ & $2(0.0)$ & $1.9(0.6)$ & $2.1(0.6)$ & $2.0(0.6)$ \\
\hline Total hours per week & $0.4(0.7)$ & $1.4(1.5)^{* *}$ & $0.3(0.6)$ & $1.5(1.3)^{*}$ & $2.0(1.9)$ & $0.9(0.9)$ \\
\hline Aerobic off water conditioning (\% participation) & 64 & 82 & 80 & 100 & 91 & 100 \\
\hline Sessions per week & $1.9(1.9)$ & $2.5(1.4)$ & $2.9(1.1)$ & $3.2(0.9)$ & $2.8(1.4)$ & $2.2(1.5)$ \\
\hline Intensity ( $1=$ low, $3=$ high $)$ & $1.7(0.6)$ & $2.2(0.5) * *$ & $1.9(0.6)$ & $2.2(0.4)$ & $2.3(0.4)$ & $2(0.5)$ \\
\hline Total hours per week & $1.9(1.9)$ & $2.6(1.8)$ & $2.3(1.5)$ & $2.9(1.6)$ & $3.3(1.9)$ & $2.1(1.8)$ \\
\hline On water conditioning (\% participation) & 86 & 86 & 100 & 90 & 100 & 93 \\
\hline Sessions per week & $2.7(1.8)$ & $4.0(1.4) * *$ & $3.4(1.6)$ & $4.1(1.8)$ & $4.4(0.8)$ & $4.0(1.5)$ \\
\hline Intensity $(1=$ low, $3=$ high $)$ & $1.8(0.5)$ & $2.3(0.6)^{* *}$ & $1.6(0.5)$ & $2.3(0.5)^{* *}$ & $2.4(0.5)$ & $2.1(0.6)$ \\
\hline Total hours per week & $8.5(6.2)$ & $10.3(5.1)$ & $9.5(5.6)$ & $11.2(5.5)$ & $13.3(3.8)$ & $8.7(4.7)^{* *}$ \\
\hline
\end{tabular}

Note:- Numbers are reported as the mean and (standard deviation).

$*=$ statistically significant $(\mathrm{p}<0.05)$.

** = statistically significant $(\mathrm{p}<0.01)$.

$* * *$ = statistically significant $(\mathrm{p}<0.001)$. 


\section{Training/race diary}

The proportion of sailor's that reported the use of a detailed training and race diary increased from 50\% in 1994 to $80 \%$ in 1995 . However, the difference was not statistically significant.

\section{Strength/circuit training}

A greater number of strength/circuit training sessions per week observed in 1995 (2.2 (S.D. 1.5) compared with 1.3 (S.D. 1.5) $(\mathrm{p}<0.05)$ in 1994) was the only significantly different result between 1994 and 1995. In 1995, 80\% participation in strength/circuit training was reported compared with 50\% participation in 1994. Mean reported intensity of training was 2.4 (S.D. 0.5) in 1995 compared with 2.0 (S.D. 0) in 1994, and the mean total hours per week participating in strength/circuit training was 2.7 (S.D. 1.9) compared with 1.5 (S.D. 2.3) in 1994.

\section{Flexibility training}

The proportion of sailors that reported participating in flexibility exercises increased from 40\% in 1994 to 80\% in $1995(\mathrm{p}<0.01)$. Likewise the mean reported total hours per week spent on flexibility training increased from 0.3 (S.D. 0.6) in 1994 to 1.5 (S.D. 1.3) in 1995 ( $p<0.05)$. The mean number of reported flexibility sessions per week increased from 1.9 (S.D. 3.4) in 1994 to 3.6 (S.D. 2.2) in 1995, However, the difference was not statistically significant.

\section{Aerobic off-water conditioning}

There were no other statistically significant differences in sailor's reported off-water conditioning between 1994 and 1995, although, reported participation, mean sessions per week, mean intensity and mean total hours per week all increased from 1994 to 1995 . However, more sailors participated in rowing in 1995 (50\%) compared with 1994 $(0 \%)(\mathrm{p}<0.01)$.

\section{On-water conditioning}

Mean reported intensity of on-water conditioning increased from 1.6 (S.D. 0.5) in 1994 to 2.3 (S.D. 0.5) in $1995(\mathrm{p}<0.01)$. Although mean reported sessions per week increased from 3.4 (S.D. 1.6) in 1994 to 4.1 (S.D. 1.8) in 1995 and mean reported total hours per week increased from 9.5 (S.D. 5.6) in 1994 to 11.2 (S.D. 5.5) in 1995, these differences were not statistically significant.

Effect of physical conditioning sport science support (SSS): Sailors who received physical conditioning sport science support had a greater mean reported strength/ circuit training intensity (2.8 (S.D. 0.4)) compared with those who received no sport science support (2.0 (S.D. $0.5))(\mathrm{p}<0.01)$ and greater reported total on-water hours per week (13.3 (S.D. 3.8)) compared with those who received no sport science support (8.7 (S.D. 4.7)) $(\mathrm{p}<0.01)$. Although sailors who received physical conditioning sport science support generally reported greater quantities and intensity of most types of training, none of the differences were statistically significantly.
Sailors' perception of sport science (all sailors in 1995)

In $1995,96 \%$ of sailors reported that they felt that their knowledge of sport science had increased. $82 \%$ reported that their use of sport science had increased (71\% in physical training, $57 \%$ in nutrition and $24 \%$ in sports psychology) and $85 \%$ of sailors reported that they believed their increased use of sport science had led to improvements in their racing performance. Examples include increased physical fitness enabling sailors to sail faster and recover more quickly, and improved nutrition giving sailors more energy to sail competitively and enabling sailors to avoid dehydration.

\section{Discussion}

This is the first study to systematically examine the changes in knowledge and use of sport science after introduction of a sport science support programme for elite dingy sailors. It builds on the only other study of knowledge and reported use of sport science amongst Olympic class sailors conducted in 1994 (Legg et al., 1997) and pre-dates the data presented in a separate paper recently published by our group (Mackie and Legg, 1999). To the authors' knowledge, there have been no other studies of this kind in other sports. The information from the present study plays an important role in providing feedback about sailors knowledge of sport science, so that improvements can be made to the quality and quantity of sport science support available to elite sailors in the future.

The sport science specialists that advised the sailors generally believed that the sailors adhered to their advice by changing their physical and psychological training sessions and nutritional habits (personal communications). There was, however, no record of sailors adherence to professional advice, so it has been assumed that all sailors practiced what they were taught. The minimal effect of SSS on sailors' knowledge and use of sport science was due to either ineffectiveness of the SSS received by sailors or by sailors not adhering to the advice given by the specialist. Although it is believed that sailors generally adhered to the advice given to them, we should not be quick to conclude that the lack of increased use of sport science by those who received SSS is due to the ineffectiveness of the sports science specialists.

\section{Nutrition}

The statistically significant increases that the sailors report for fluid taken and consumed on a four hour sail between 1994 to 1995 indicate that there has been an improvement in sailor's nutritional habits over this time. This improvement may have been influenced by the 18 new comers to the subject group in 1995 as the comparison for the 10 subjects common to 1994 and 1995 showed no such statistically significant increases. Although there were increases in the amount of fluid taken and consumed on a 
four hour sail in the latter group, the small sample size will have reduced the chances of the result being statistically significant. The lack of differences between those subjects who received nutrition SSS and those who received no SSS, suggest that nutrition SSS had little to do with any changes in nutritional habits observed between 1994 and 1995.

Sailor's increased fluid intake seems consistent with $75 \%$ of sailors in 1995 reporting having experienced dehydration. Suffering the effects of dehydration during a race would be a good reason to increase the amount of fluid drunk subsequently. The increased mean reported fluid intake in 1995 is pleasing as it suggests that sailors are becoming more aware of the harmful effects of dehydration that can easily develop during sailing due to exposure to sun and wind, and the layers of clothing usually worn, especially in hot climates. Increased fluid intake will also help to prevent heat strain, which is also a danger when sailing in a hot environment.

\section{Psychology}

Apart from sailors feeling less anxious before a race in 1995 than they did in 1994, there seemed to be no improvement in sailors psychological performance. The fact that sailors who received psychology SSS were significantly more anxious before races suggests that sports psychology consultations had no part to play in sailors feeling less anxious before a race in 1995. These results are consistent with the low percentage $(24 \%)$ of sailors reporting increased use of sports psychology.

The lack of improvement in sailors answers to psychology questions and use of sport psychology between 1994 and 1995 should be of some concern to the sailing sport psychologist. Because dinghy racing is a very tactically and strategically orientated sport, being in the optimal mental state through use of psychological techniques should be a high priority for sailors. Increased use of sport psychology in a form that is useful to the sailor would help dinghy sailors to have less negative thoughts, get less angry at other sailors, improve concentration at the end of a race and get less frustrated when they make mistakes. The large proportion of sailors in 1994 and 1995 reporting using Relaxation and Visualisation is a positive finding, although it would be expected that sailor's reported anxiety, negative thoughts, frustration and loss of concentration would improve as a result. Perhaps sailors are not using relaxation and visualisation effectively, or they need to use other psychological techniques to help improve their state of mind before and during racing.

\section{Physical conditioning}

Significant increases in volume and intensity of physical conditioning by all subjects in 1995 and those subjects common to 1994 and 1995 clearly indicates that there were real improvements in the physical conditioning habits of the sailors. Also the observation that $71 \%$ of sailors reported that their physical conditioning had increased and become more sailing specific is additional support for the reality of improvements in physical conditioning. These improvements are encouraging, as it shows that sailors are acknowledging that physical fitness is just as important a component to race preparation as is boat tuning, knowledge of the sailing rules, or the development of a race strategy. However, the lack of statistically significant differences between those sailors who received physical conditioning SSS and those sailors who did not, suggest that it is not clear whether the improvements in sailor's physical conditioning habits are attributable to the SSS they received or whether their improvements are a result of a years improved knowledge from other sources such as fellow sailors, other physical conditioners, or books and magazines.

\section{Conclusion}

In conclusion, elite New Zealand dinghy sailors have improved their nutrition and physical training habits. Apart from sailors feeling less anxious before racing in 1995 than in 1994, there appeared to be no other improvements in sailors psychological practices. Whether these results are a result of the advice given by specialists in sports science is unclear. However, most of the sailors believed that their knowledge and use of sport science had increased (mainly in physical conditioning) and this had led to improvements in their racing performance. Sailors are clearly becoming more aware of sport science and how it can help them. However, there is still room for improvement, especially in sport psychology.

Acknowledgments. The authors are grateful for the support of Yachting New Zealand, Sport Science New Zealand, the sailors who participated in this study and Nick Park for assistance with data analysis. Funding was provided by the Hillary Commission for Sport, Fitness and Leisure.

\section{References}

Bachemont F, Fouillot J, Izou M, Terkaia M, Drobzowski $\mathrm{T}$ (1984) Etude de la fréquence cardiaque en dériveur et planche à voile par monitoring ambulatoire. Union Médicale du Canada 113: 644-647

Beillot J, Rochconger P, Briend G, Mazer J, LeBars R (1979) Apprôche biomécanique de la position de Rappel. Lyon Mediterranée Médical 15: 1283-1279

Beillot J, Rochconger P, Gouard P, Simonet J, Briend G (1981) Le rappel sur Finn: approche biomécanique. Cinésiologie 80: 179-191

Blackburn M (1994) Physiological responses to $90 \mathrm{~min}$ of simulated dinghy sailing. Journal of Sport Science 14: $131-137$ 
De Vito G, Di Filippo L, Felici A, Gallozzi C, Madaffari A, Marino S, Rodio A (1996) Assessment of energetic cost in Laser and Mistral sailor. International Journal of Sports Cardiology 5: 55-59

De Vito G, Di Filippo L, Rodio A, Felici F, Madaffari A (1997) Is the Olympic boardsailor an endurance athlete? International Journal of Sports Medicine 18: 281-284

Gallozzi C, Fanton F, De Angelis M, Dal Monte A (1993) The energetic cost of sailing. Medicine and Science Research 21: 851-853

Harrison J, Burstyn P, Coleman S, Hale T (1988) A comparison of heart rate/oxygen uptake relationship for cycle and dinghy ergometry. Journal of Sports Science 6: 160

Legg SJ, Smith PA, Slyfield D, Miller AB, Wilcox H, Gilberd C (1997) Knowledge and reported use of sport science by elite New Zealand Olympic Class sailors. Journal of Sports Medicine and Physical Fitness 37: 215-217

Legg SJ, Smith PA, Slyfield D, Miller AB, Wilcox H, Gilberd C, Tate C (1997) Physical performance of New Zealand and other national elite Olympic class sailors. Journal of Sports Medicine and Physical Fitness 37: 41-49

Mackie HW, Legg SJ (1999) A preliminary quantitative assessment of the force demands in laser racing. Journal of Science and Medicine in Sport 2: 78-85

Mackie HW, Sanders RH, Legg SJ (1999) The physical demands of Olympic yacht racing. Journal of Science and Medicine in Sport 2: 375-388

Mackie HW, Legg SJ (1999) Development of knowledge and reported use of sport science by elite New Zealand Olympic Class sailors. Journal of Physiological Anthropology 18: 125-133

Marchetti M, Figura F, Ricci B (1980) Biomechanics of two fundamental sailing postures. Journal of Sports Medicine and Physical Fitness 20: 325-332

Niinimaa V, Wright G, Shephard R, Clarke J (1977) Characteristics of the successful dinghy sailor. Journal of Sports Medicine and Physical Fitness 17: 83-96

Plyley MJ, Davis GM, Shephard RJ (1985) Body profile of Olympic Class Sailors. Physician and Sports Medicine 13: $152-167$

Pudenz V, Dierck TH, Rieckert H (1981) Heart rate frequency as a reflection of the length of the boat race course - an experimental study of load imposed during laser sailing. Deutsche Zeitschrift für Sportmedizin, 32: 192-195

Putnam CA (1979) A mathematical model of hiking positions in a sailing dinghy. Medicine and Science in Sports 11: 288-292

Shepard RJ (1990) The Biology and Medicine of Sailing. Sports Medicine 9: 86-99

Spurway NC, Burns R (1993) Comparison of dynamic and static fitness-training programmes for dinghy sailors - and some questions concerning the physiology of hiking. Medicine in Science and Research 21: 865-867

Vogiatzis I, Roach NK, Trowbridge EA (1993) Cardiovascular, muscular and blood lactate responses during dinghy hiking. Medicine in Science and Research 21: 861-863

Vogiatzis I, Spurway NC, Wilson J (1994) On-water oxygen uptake measurements during dinghy sailing. Journal of Sports Science 12: 153

Wright GR, Clarke R, Niinimaa V, Shephard RJ (1976) Some reaction to a dry land training programme for dinghy sailors. British Journal of Sports Medicine 10: $4-10$

Received: May 24, 1998

Accepted: January 14, 2000

Correspondence to: S.J. Legg, Department of Management Systems, Massey University, Palmerston North, New Zealand

e-mail:s.j.legg@massey.ac.nz 